\title{
Risk factors for long-term mortality in patients admitted with severe infection
}

\begin{abstract}
Background: Severe infection is a main cause of mortality. We aim to describe risk factors for long-term mortality among inpatients with severe infection.

Methods: Prospective cohort study in a 600-bed university hospital in Portugal including all patients with severe infection admitted into intensive care, medical, surgical, hematology and nephrology wards over one-year period. The outcome of interest was 5-year mortality following infection. Variables of patient background and infectious episode were studied in association with the main outcome through multiple logistic regression. There were 1013 patients included in the study. Hospital and 5-year mortality rates were 14 and 37\%, respectively.
\end{abstract}

Results: Two different models were developed (with and without acute-illness severity scores) and factors independently associated with 5-year mortality were [adjusted odds ratio (95\% confidence interval)]: age $=1.03$ per year (1.02-1.04), cancer $=4.36$ (1.65-11.53), no comorbidities $=0.4$ (0.26-0.62), Karnovsky Index $<70=2.25$ (1.48-3.40), SAPS (Simplified Acute Physiology Score) $\|=1.05$ per point (1.03-1.07), positive blood cultures $=1.57(1.01-2.44)$ and infection by an ESKAPE pathogen (Enterococcus faecium, Staphylococcus aureus, Klebsiella pneumoniae, Acinetobacter baumannii, Pseudomonas aeroginosa and Enterobacter species) = 1.61 (1.00- 2.60); and in the second model [without SAPS II and SOFA (Sequential Organ Failure Assessment) scores]: age $=1.04$ per year (1.03-1.05), cancer $=5.93$ (2.26-15.51), chronic haematologic disease $=2.37$ (1.14-4.93), no comorbidities $=0.45$ (0.29-0.69), Karnovsky Index $<0=2.32(1.54-3.50)$, septic shock [reference is infection without SIRS (Systemic Inflammatory Response Syndrome)] $=3.77(1.80-7.89)$ and infection by an ESKAPE pathogen = 1.61 (1.00-2.60). Both models presented a good discrimination power with an AU-ROC curve $(95 \% \mathrm{Cl})$ of $0.81(0.77-0.84)$ for model 1 and $0.80(0.76-0.83)$ for model 2 . If only patients that survived hospital admission are included in the model, variables retained are: age $=1.03$ per year $(1.02-1.05)$, cancer $=4.69(1.71-12.83)$, chronic respiratory disease $=2.27(1.09-4.69)$, diabetes mellitus $=1.65(1.06-2.56)$, Karnovsky Index $<70=2.50(1.63-3.83)$ and positive blood cultures $=1.66(1.04-2.64)$ with an AU-ROC curve of $0.77(0.73-0.81)$.

Conclusions: Age, previous comorbidities, and functional status and infection by an ESKAPE pathogen were consistently associated with long-term prognosis. This information may help in the discussion of individual prognosis and clinical decision-making.

Keywords: Severe infection, Risk factors for long-term mortality, 5-year mortality, ESKAPE pathogens

\footnotetext{
* Correspondence: joaop.dinis@gmail.com

${ }^{1}$ Serviço de Medicina, Hospital de Santo António, Largo Prof. Abel Salazar,

4099-001 Porto, Portugal

Full list of author information is available at the end of the article
} International License (http://creativecommons.org/licenses/by/4.0/), which permits unrestricted use, distribution, and reproduction in any medium, provided you give appropriate credit to the original author(s) and the source, provide a link to the Creative Commons license, and indicate if changes were made. The Creative Commons Public Domain Dedication waiver (http://creativecommons.org/publicdomain/zero/1.0/) applies to the data made available in this article, unless otherwise stated. 


\section{Background}

Severe infection is the leading cause of non-scheduled hospital admission [1]. Depending on the severity of infection mortality rate can be as high as 60\% in septic shock patients [2].

But consequences of severe infection extend well beyond the first month following it, with an increased mortality during at least the first year [3].

Prognostic factors associated with sepsis are well studied by many authors, especially among the Intensive Care Unit (ICU) population, but even in this specific population they all refer to short term mortality (ICU [4], hospital $[1,5]$ ' or 28-day mortality [6]). Age [4, 7], comorbidities $[2,4-6]$, severity of acute illness $[2,4,8]$, focus of infection $[2,4,6,9]$, place of acquisition (community, hospital or ICU-acquired) [2,5] and infection by specific organisms $[2,4]$ have been nominated as potential risk factors in this sub-population.

Since many patients admitted to hospital with infection have important concomitant medical conditions that may influence long-term prognosis it seems important to study long-term mortality.

As far as we know there are no studies on long-term prognostic factors in general hospital patients with infection. The aim of the current study is to determine independent risk factors for 5-year mortality in hospitalized patients with severe infection.

\section{Methods}

\section{Ethics statement}

This study was approved by the Institutional Review Board of Hospital de Santo António, Oporto Hospital Centre, Portugal, and informed consent was waived due to the observational nature of the study.

\section{Study design and patient population}

Prospective cohort study conducted at a 600-bed tertiary care university hospital, over 1-year period (1st June 2008 to 31st May 2009). All consecutive adult patients admitted to the medical, surgical, nephrology or hematology wards of the hospital or to the intensive care unit (ICU) that had a diagnosis of infection were included, based on the Center for Disease Control (CDC) criteria [10]. Infections were classified as community-acquired (CAI), healthcareassociated (HCAI) or hospital-acquired, according to the place of acquisition. Long term mortality was defined as mortality 5 years after the infection diagnosis.

Data concerning mortality was obtained from SClinico Hospitalar, an informatic tool connected to a national network that gathers healthcare information nationwide.

\section{Definitions}

Severe infection was defined as an infection which led to hospital admission (with or without sepsis criteria).
CAI was defined as an infection detected within $48 \mathrm{~h}$ of hospital admission in patients who did not fit the criteria for a HCAI.

HCAI was defined using the same criteria of Deborah Friedman [11], an infection present at the time of hospital admission or within $48 \mathrm{~h}$ of admission in patients that fulfilled any of the following criteria:

- received intravenous therapy at home, wound care or specialized nursing care through a healthcare agency, family or friends; or, self-administered intravenous medical therapy in the 30 day period before the onset of the infection;

- attended a hospital or haemodialysis clinic, or received intravenous chemotherapy in the previous 30 days;

- were hospitalized in an acute care hospital for 2 or more days in the previous 90 days;

- resided in a nursing home or long-term care facility.

HAI was defined as a localized or systemic condition that resulted from an adverse reaction to the presence of an infectious agent(s) or its toxin(s), and that occurred $48 \mathrm{~h}$ or more after hospital admission and was not incubating at the time of admission [10]. Infections in patients recently discharged from the hospital within the previous 2-week period were also included in this group.

The CDC definitions were used to define infections at different anatomic sites [10].

We grouped Enterococcus faecium vancomycinresistant, methicillin-resistant Staphylococcus aureus (MRSA), extended-spectrum beta-lactamase (ESBL) producer Escherichia coli (E. coli) and Klebsiella species, Klebsiella pneumoniae Carbapenamase-hydrolyzing and multidrug resistant (MDR) Acinectobacter baumannii, Pseudomonas aeruginosa and Enterobacter species in a group denominated ESKAPE [12].

The presence of ESBL production among $E$. coli and Klebsiella spp. strains was screened by the automatic analyzer Vitek2 (BioMérieux). It was always confirmed by a disk diffusion test that detects synergism between the cephalosporins/monobactam and clavulanate. If the interpretation of the results was doubtful we also performed Etest ${ }^{\oplus}$ : the combination strains of cefotaxime and cefotaxime/clavulanate and ceftazidime and ceftazidime/clavulanate allows the detection of ESBL whenever the ratio antibiotic/antibiotic + inhibitor is equal or above 8 .

The presence of carbapenemase production in Enterobacteriaceae was suspected whenever MIC's for ertapenem, imipenem and meropenem exceed $0.5,1$ and $1 \mu \mathrm{g} / \mathrm{mL}$, respectively. In such cases, a modified Hodge test was performed, and the ultimate confirmatory test was carbapenemase detection by molecular methods. 
Table 1 General characteristics patients included in the study and its association with 5 year mortality

\begin{tabular}{|c|c|c|c|c|}
\hline Variable & Total & Dead at 5 years & Crude OR (95\% Cl) & $p$ value \\
\hline Age, median $\pm S D$, years & $65 \pm 20$ & $74 \pm 14$ & 1.05 (1.04-1.05), per year & $<0.001$ \\
\hline Female, n (\%) & $517(51)$ & $190(50)$ & $1.06(0.82-1.37)$ & 0.656 \\
\hline \multicolumn{5}{|l|}{ Underlying conditions, n (\%) } \\
\hline Diabetes mellitus & $198(20)$ & $85(22)$ & $1.33(0.97-1.83)$ & 0.074 \\
\hline Atherosclerosis & $236(23)$ & $127(34)$ & $2.43(1.80-3.27)$ & $<0.001$ \\
\hline Immunosuppression & $219(22)$ & $75(20)$ & $0.84(0.61-1.15)$ & 0.274 \\
\hline Chemotherapy & $35(4)$ & $26(7)$ & & \\
\hline Radiotherapy & $8(1)$ & $6(2)$ & & \\
\hline Long-term corticoid & $168(17)$ & $46(12)$ & & \\
\hline Short-term corticoid & $22(2)$ & $11(3)$ & & \\
\hline HIV positive (non-AIDS) & $6(1)$ & $1(0)$ & & \\
\hline AIDS & $3(0)$ & $2(1)$ & & \\
\hline Chronic liver disease & $22(2)$ & $14(4)$ & $3.00(1.25-7.22)$ & 0.014 \\
\hline Chronic heart failure & $74(7)$ & $44(12)$ & $2.64(1.63-4.29)$ & $<0.001$ \\
\hline Chronic respiratory disease & $66(7)$ & $43(11)$ & $3.40(2.01-5.74)$ & $<0.001$ \\
\hline Chronic kidney disease & $148(15)$ & $56(15)$ & $1.02(0.71-1.46)$ & 0.908 \\
\hline End Stage kidney disease & $69(7)$ & $23(6)$ & $0.83(0.49-1.39)$ & 0.469 \\
\hline Cancer & $45(4)$ & $36(10)$ & $7.29(3.47-15.41)$ & $<0.001$ \\
\hline Haematologic cancer & $59(6)$ & $35(9)$ & $2.59(1.51-4.42)$ & 0.001 \\
\hline No comorbidities & $352(35)$ & $78(21)$ & $0.34(0.25-0.46)$ & $<0.001$ \\
\hline Karnofsky Index < 70 & $311(31)$ & $195(52)$ & $4.73(3.56-6.29)$ & $<0.001$ \\
\hline Type of infection & & & & $<0.001$ \\
\hline Community & $483(48)$ & $144(38)$ & 1.0 & \\
\hline Healthcare associated & $219(22)$ & $106(28)$ & $2.21(1.59-3.07)$ & \\
\hline Hospital-acquired & $311(31)$ & $129(34)$ & $1.67(1.24-2.25)$ & \\
\hline Severity of infection & & & & $<0.001$ \\
\hline Infection & $275(27)$ & $86(23)$ & 1.0 & \\
\hline Sepsis & $355(35)$ & $125(33)$ & $1.19(0.85-1.67)$ & \\
\hline Severe sepsis & $292(29)$ & $116(31)$ & $1.45(1.02-2.05)$ & \\
\hline Septic shock & $91(9)$ & $52(14)$ & $2.93(1.80-4.77)$ & \\
\hline SAPS I| score, per point & $29 \pm 13$ & $35 \pm 14$ & $1.07(1.06-1.09)$ & $<0.001$ \\
\hline SOFA score, per point & $2 \pm 3$ & $3 \pm 3$ & $1.11(1.06-1.16)$ & $<0.001$ \\
\hline Focus of infection & & & & 0.043 \\
\hline Respiratory & $407(40)$ & $156(41)$ & 1.0 & \\
\hline Urinary & $339(34)$ & $134(35)$ & $1.05(0.78-1.41)$ & \\
\hline Abdominal & $209(21)$ & $62(16)$ & $0.68(0.47-0.97)$ & \\
\hline Other & $19(2)$ & $14(4)$ & $1.40(0.81-2.43)$ & \\
\hline Microbiologic documentation & $691(68)$ & $276(73)$ & $1.41(1.07-1.87)$ & 0.015 \\
\hline Positive blood cultures & $151(15)$ & $70(19)$ & $1.55(1.09-2.19)$ & 0.014 \\
\hline Infection by a MDR pathogen & $322(51)$ & $146(56)$ & $1.42(1.03-1.95)$ & 0.031 \\
\hline Infection by an ESKAPE pathogen & $113(18)$ & $61(24)$ & $1.88(1.25-2.83)$ & 0.003 \\
\hline Inappropriate antibiotherapy & $144(21)$ & $73(26)$ & $1.74(1.20-2.52)$ & 0.003 \\
\hline
\end{tabular}

CI Confidence interval, SD Standard deviation, HIV Human immunodeficiency virus, AIDS Acquired immunodeficiency syndrome, OR Odds ratio 
Table 2 Isolated infectious agents

\begin{tabular}{|c|c|c|}
\hline Isolated microorganisms, n (\%) & Total & Dead at 5 years \\
\hline Community-acquired infection & $272(56)$ & $93(65)$ \\
\hline Escherichia coli & $101(10)$ & $39(10)$ \\
\hline Streptococcus pneumoniae & $59(6)$ & $18(5)$ \\
\hline Haemophilus influenza & $17(2)$ & $3(1)$ \\
\hline Proteus mirabillis & $12(1)$ & $5(1)$ \\
\hline Klebsiella pneumoniae & $11(1)$ & $5(1)$ \\
\hline Pseudomonas aeroginosa & $10(10)$ & $5(1)$ \\
\hline Enterococcus faecium & $7(0)$ & $4(1)$ \\
\hline MSSA & $7(0)$ & $2(1)$ \\
\hline Legionella pneumophyla & $6(0)$ & $0(0)$ \\
\hline Other & $42(4)$ & $21(6)$ \\
\hline ESKAPE & $10(10)$ & $5(1)$ \\
\hline MDR & $79(8)$ & $36(10)$ \\
\hline Healthcare-associated infection & $160(73)$ & $76(72)$ \\
\hline Escherichia coli & $69(7)$ & $29(8)$ \\
\hline MSSA & $21(2)$ & $9(2)$ \\
\hline Klebsiella pneumoniae & $15(2)$ & $6(2)$ \\
\hline Pseudomonas aeroginosa & $11(1)$ & $6(2)$ \\
\hline Enterococcus faecalis & $9(0)$ & $4(1)$ \\
\hline MRSA & $8(0)$ & $6(2)$ \\
\hline Proteus mirabillis & $7(0)$ & $4(1)$ \\
\hline Streptococcus pneumoniae & $7(0)$ & $5(1)$ \\
\hline Enterococcus faecium & $6(0)$ & $4(1)$ \\
\hline Other & $31(3)$ & $18(5)$ \\
\hline ESKAPE & $30(3)$ & $16(4)$ \\
\hline MDR & $85(8)$ & $44(12)$ \\
\hline Hospital-acquired infection & $259(833)$ & $107(83)$ \\
\hline Escherichia coli & $68(7)$ & $24(6)$ \\
\hline Pseudomonas aeroginosa & $37(4)$ & $18(2)$ \\
\hline MRSA & $30(3)$ & $18(5)$ \\
\hline Enterococcus faecalis & $24(2)$ & $9(2)$ \\
\hline Klebsiella pneumoniae & $23(2)$ & $7(2)$ \\
\hline MSSA & $18(2)$ & $3(1)$ \\
\hline Proteus mirabillis & $17(2)$ & $8(2)$ \\
\hline Enterobacter cloacae & $16(2)$ & $8(0)$ \\
\hline Acinetobacter baumanni & $13(1)$ & $4(0)$ \\
\hline Enterococcus faecium & $13(1)$ & $7(2)$ \\
\hline Candida albicans & $7(0)$ & $0(0)$ \\
\hline Morganella morganni & $6(0)$ & $1(0)$ \\
\hline Clostridium difficile & $5(0)$ & $3(1)$ \\
\hline Enterobacter aerogenes & $5(0)$ & $2(1)$ \\
\hline
\end{tabular}

Table 2 Isolated infectious agents (Continued)

\begin{tabular}{lll}
\hline Isolated microorganisms, $\mathrm{n}(\%)$ & Total & Dead at 5 years \\
\hline Serratia marcescens & $5(0)$ & $3(1)$ \\
Other & $24(2)$ & $14(4)$ \\
ESKAPE & $73(7)$ & $10(3)$ \\
MDR & $158(16)$ & $79(21)$ \\
\hline $\begin{array}{l}\text { MSSA Methicillin-sensitive Staphylococcus aureus, MRSA Methicillin-resistant } \\
\text { Staphylococcus aureus, ESKAPE Enterococcus faecium, MRSA, ESBL Klebsiella } \\
\text { pneumoniae, Acinetobacter baumannii, Pseudomonas aeruginosa and Enterobacter } \\
\text { species; MDR Multidrug resistant bactéria }\end{array}$
\end{tabular}

The comorbidities studied included immunosuppression (administration of chemotherapy in the 12 months prior to hospital admission, either radiation therapy or administration of $0.2 \mathrm{mg} / \mathrm{kg} / \mathrm{day}$ of prednisolone for at least 3 months prior to hospital admission, administration of $1 \mathrm{mg} / \mathrm{kg} /$ day of prednisolone for 1 week in the 3 months prior to hospital admission or infection with human immunodeficiency virus), chronic liver disease [13], chronic heart failure [13], chronic respiratory disease [13], hematological disease [14], cancer [14], diabetes mellitus requiring insulin therapy or oral hypoglycaemic agents before the infection and/or atherosclerosis (defined as a previous history of a transient ischemic attack, stroke, angina, myocardial infarction or peripheral arterial disease).

Functional performance status was assessed by the Karnofsky index [15]. A score of lower than 70 implies that the patient is unable to perform normal activities or do active work.

For the first day of antibiotic therapy, the acute physiological scores, The Simplified Acute Physiology Score (SAPS II) [14] and Sepsis-related Organ failure Assessment (SOFA) were recorded [16].

The initial empirical antibiotic treatment was considered "adequate" if the initial antibiotic prescribed within the $24 \mathrm{~h}$ matched in vitro susceptibility of a pathogen deemed to be the likely cause of infection and when the dosage and route of administration were appropriate for current medical status (focus and severity of infection); only patients with positive microbiology will be considered in this analysis.

\section{Statistical analysis}

Continuous variables are described as means and standard deviations (SD), categorical variables are described with absolute frequencies and percentages. Student T-tests or Mann-Whitney tests are used to compare continuous values between types of infection. For categorical variables these comparisons are performed using Pearson $X^{2}$ test.

Variables associated with long term mortality were studied through logistic regression. Variables studied through the multiple regression logistic model were: 
age, functional status (Karnofsky Index), diabetes, atherosclerosis, cancer, type of infection (community, healthcare associated or hospital acquired), severity of infection, SAPS II and SOFA scores calculated for the day of infection diagnosis, site of infection, microbiological documentation of infection, positive blood cultures, infection by a multidrug resistant pathogen or an infectious agent from the group ESKAPE and inappropriate antibiotic therapy. Those with a clear association in the univariate analysis ( $p$-value $<0.1)$ or considered clinically significant were selected for the multivariable analysis. The results of the multivariable models are expressed as odds ratio (OR) with 95\% confidence interval $\left(\mathrm{CI}_{95 \%}\right)$ and $p$-values. The accuracy of the models was assessed by the area under the receiver operating characteristics curve (AU-ROC) and calibration was tested using the Hosmer-Lemeshow goodness-of-fit test. The significance level was defined as $p<0.05$.

Data were analysed using SPSS, version 18 for Windows (Chicago, IL).

\section{Results}

There were 1035 records included in the initial study, 22 (2\%) were excluded from the present analysis due to insufficient data regarding long-term outcome. Of the
1013 patients included, 86\% $(n=868)$ were recruited in the ward and $14 \%(n=145)$ in ICU.

Mean \pm SD age of included patients was $65 \pm 20$ years and $51 \%$ were female $(n=517)$. Most of them, $65 \%$ $(n=661)$ had at least one comorbidity and $30 \%(n=300)$ had more than one (Table 1).

The most common foci of infection were respiratory, urinary and intra-abdominal (Table 1). Overall isolation rate was $68 \%(n=691)$ (Table 2$)$. Initial antibiotic therapy was inadequate in $18 \%(n=179)$ of the patients included.

Severity of acute illness was documented by a median \pm SD SAPS II and SOFA scores of $30 \pm 13$ and $2 \pm 3$, respectively. Hospital and 5-year mortality rates were $14 \%$ $(n=137)$ and $37 \%(n=379)$, respectively.

Variables associated with 5-year mortality in the univariate analysis were: age, the presence of comorbidities, namely: diabetes, atherosclerosis, chronic liver disease, chronic heart failure, chronic respiratory failure, solid tumours and haematologic cancer, Karnofsky index $<70$, type of infection, severity of infection, SAPS II and SOFA scores, focus of infection, microbiologic documentation of infection, positive blood cultures, infection by a MDR pathogen or a pathogen from the group ESKAPE and inappropriate initial antibiotic therapy

Table 3 Independent risk factors associated with long term death in patients admitted with severe infection

\begin{tabular}{|c|c|c|c|c|}
\hline \multirow[t]{2}{*}{ Variable } & \multirow[t]{2}{*}{ Total } & \multirow{2}{*}{$\begin{array}{l}\text { Dead at } \\
5 \text { years }\end{array}$} & \multicolumn{2}{|c|}{ Adjusted OR (95\% Cl) } \\
\hline & & & Model 1 & Model 2 \\
\hline Age, mean $\pm S D$, per year & $65 \pm 20$ & $74 \pm 14$ & $\begin{array}{l}1,03 \\
(1.02-1.04)\end{array}$ & $\begin{array}{l}1,04 \\
(1.03-1.05)\end{array}$ \\
\hline Cancer, n (\%) & $45(4)$ & $36(10)$ & $\begin{array}{l}4.36 \\
(1.65-11.53)\end{array}$ & $\begin{array}{l}5.93 \\
(2.26-15.51)\end{array}$ \\
\hline Chronic haematologic disease, $\mathrm{n}(\%)$ & $59(6)$ & $35(9)$ & & $\begin{array}{l}2.37 \\
(1.14-4.93)\end{array}$ \\
\hline No comorbidities, n (\%) & $352(35)$ & $78(21)$ & $\begin{array}{l}0.40 \\
(0.26-0.62)\end{array}$ & $\begin{array}{l}0.45 \\
(0.29-0.69)\end{array}$ \\
\hline Karnofsky Index < 70, n (\%) & $311(31)$ & $195(52)$ & $\begin{array}{l}2.25 \\
(1.48-3.40)\end{array}$ & $\begin{array}{l}2.32 \\
(1.54-3.50)\end{array}$ \\
\hline \multicolumn{5}{|l|}{ Severity of infection, n (\%) } \\
\hline Infection & $275(27)$ & $86(23)$ & & 1.00 \\
\hline Sepsis & $355(35)$ & $125(33)$ & & $\begin{array}{l}1.15 \\
(0.72-1.83)\end{array}$ \\
\hline Severe sepsis & $292(29)$ & $116(31)$ & & $\begin{array}{l}1.33 \\
(0.81-2.17)\end{array}$ \\
\hline Septic shock & $91(9)$ & $52(14)$ & & $\begin{array}{l}3.77 \\
(1.80-7.89)\end{array}$ \\
\hline SAPS $I I$, median $\pm S D$, per point & $29 \pm 13$ & $35 \pm 14$ & $\begin{array}{l}1.05 \\
(1.03-1.07)\end{array}$ & \\
\hline Positive blood cultures, n (\%) & $151(15)$ & $70(19)$ & $\begin{array}{l}1.57 \\
(1.01-2.44)\end{array}$ & \\
\hline Infection by an ESKAPE pathogen, n (\%) & $113(18)$ & $61(24)$ & $\begin{array}{l}1.61 \\
(1.00-2.60)\end{array}$ & $\begin{array}{l}1.61 \\
(1.00-2.60)\end{array}$ \\
\hline
\end{tabular}


(Table 1). The final model retained: age, cancer, absence of known comorbidities, Karnofsky index $<70$, SAPS II, positive blood cultures and infection by a pathogen from the ESKAPE group (Model 1, Table 3). A second model without SAPS II and SOFA scores was built and the same variables were retained plus haematologic disease and severity of infection (Model 2, Table 3). The AU-ROC curve was 0.81 (0.77-0.84) and $0.80(0.76-0.83)$ for the first and second models, respectively (Fig. 1).

A third model considering only patients that were discharged alive from the hospital was made and results are shown in Table 4. The variables retained were: age, comorbidities (cancer, chronic respiratory disease and diabetes mellitus), karnofsky index $<70$ and positive blood cultures (Table 4). The AU-ROC curve was 0.77 (0.73-0.81) (Fig. 1).

\section{Discussion}

The 5-year mortality rate in our cohort was $37 \%$. Previous articles have described a 5-year mortality between 39 and 74\% [17-21]. This difference could be explained partially by the implementation of the Surviving Sepsis Campaign in 2004 that resulted in a consistent decrease in mortality due to severe infection/sepsis [22].

Hospital mortality rate was $14 \%$, lower than described by previous authors that considered only patients admitted into ICU [2].
In general, predictors of long-term mortality found in this study are similar to those from other studies, like: age [20, 23-27], comorbidities [19, 20, 23-26], functional status [23], severity of infection [20, 23], SAPS II, positive blood cultures and infection by an ESKAPE pathogen. The association of an infection by a pathogen from the ESKAPE group with long-term mortality has not been described previously, as far as the authors are aware.

One surprising result was the fact that inappropriate antibiotic therapy was not retained as an independent prognostic factor, although this was shown to influence long-term mortality following bacteraemia [20, 23], but given the high proportion of patients that received appropriate antibiotic therapy in the first $24 \mathrm{~h}$ its impact in this cohort may be less evident.

In patients that survived hospital admission the infection-related risk factors were less significant, aside from positive blood cultures, and patient related factors were more relevant like age, comorbidities and functional status.

In the acute setting it is reasonable to expect infection to be the dominant cause of death. However in longterm mortality infection may play less of a direct role. Maybe it can be due to a combination of pre-existing co-morbidities, intensities of therapy (and its iatrogenic effects) the nature and severity of initial infection and the complications of the acute disease. Therefore the

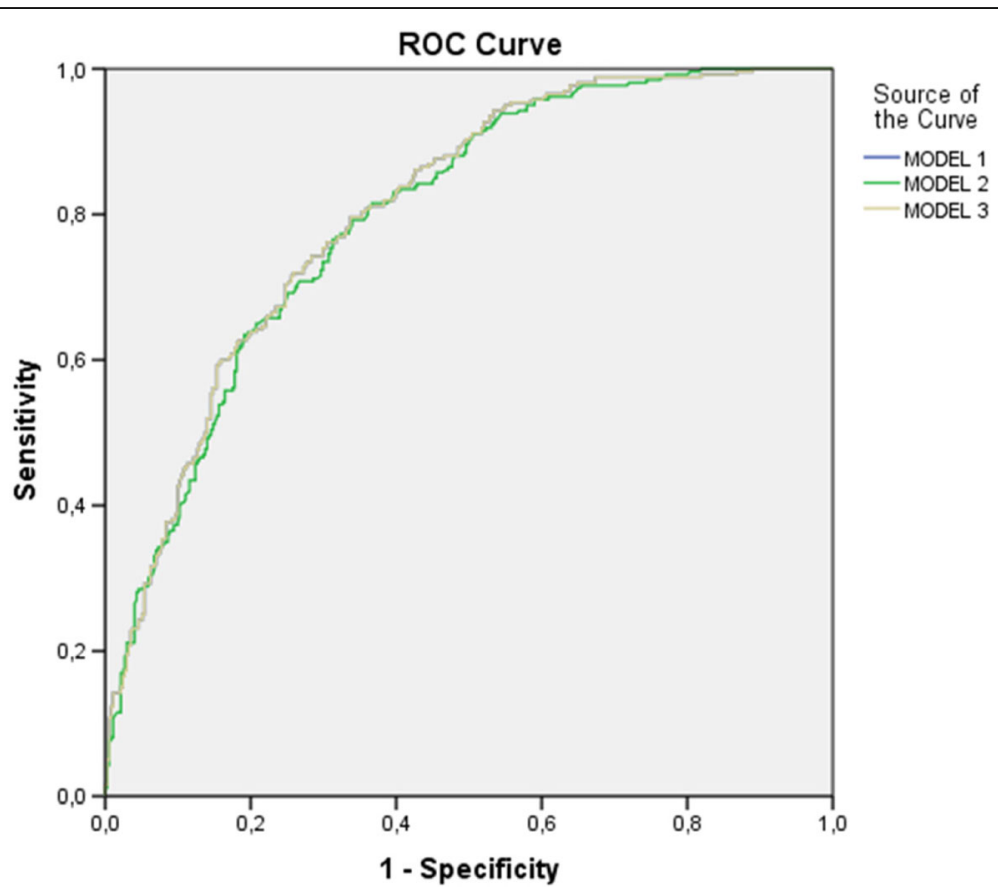

Fig. 1 Area under the receiver operating characteristics (AU-ROC) curve $(95 \% \mathrm{Cl})$ for the final models. Model 1: all patients with acute severity scores (SPAS II and SOFA): 0.81 (0.77-0.84). Model 2: all patients without acute severity scores: 0.80 (0.76-0.83). Model 3: only patients that survived hospital admission: 0.77 (0.73-0.81) 
Table 4 Characteristics of the group of patients discharged alive and its association with 5 year mortality

\begin{tabular}{|c|c|c|c|c|c|}
\hline Variable & $\begin{array}{l}\text { Total } \\
(n=876)\end{array}$ & $\begin{array}{l}\text { Dead at } 5 \text { years } \\
(n=243)\end{array}$ & $\begin{array}{l}\text { Crude OR } \\
(95 \% \mathrm{Cl})\end{array}$ & $p$ value & $\begin{array}{l}\text { Adjusted OR } \\
(95 \% \mathrm{Cl})\end{array}$ \\
\hline Age, median $\pm S D$, years & $63 \pm 20$ & $73 \pm 14$ & 1.04 (1.03-1.05), per year & $<0.001$ & 1.03, per year (1.02-1.05) \\
\hline Female, n (\%) & $458(52)$ & $132(54)$ & $0.89(0.66-1.20)$ & 0.454 & \\
\hline \multicolumn{6}{|l|}{ Underlying conditions, n (\%) } \\
\hline Diabetes mellitus & $183(21)$ & $70(29)$ & $1.86(1.32-2.63)$ & $<0.001$ & $1.65(1.06-2.56)$ \\
\hline Atherosclerosis & $283(21)$ & $74(31)$ & $2.11(1.50-2.96)$ & $<0.001$ & \\
\hline Immunosuppression & $195(22)$ & $51(21)$ & $0.90(0.63-1.29)$ & 0.575 & \\
\hline Chemotherapy & $26(3)$ & $17(7)$ & & & \\
\hline Radiotherapy & $6(1)$ & $4(2)$ & & & \\
\hline Long-term corticoid & $166(18)$ & $34(14)$ & & & \\
\hline Short-term corticoid & $16(2)$ & $5(2)$ & & & \\
\hline HIV positive (non-AIDS) & $6(1)$ & $1(0)$ & & & \\
\hline AIDS & $2(0)$ & $1(0)$ & & & \\
\hline Chronic liver disease & $14(2)$ & $6(3)$ & $1.98(0.68-5.76)$ & 0.211 & \\
\hline Chronic heart failure & $62(7)$ & $33(14)$ & $3.27(1.94-5.52)$ & $<0.001$ & \\
\hline Chronic respiratory disease & $66(7)$ & $43(11,4)$ & $4.17(2.39-7.26)$ & $<0.001$ & $2.27(1.09-4.69)$ \\
\hline Chronic kidney disease & $138(16)$ & $46(19)$ & $1.37(0.93-2.03)$ & 0.111 & \\
\hline End Stage kidney disease & $66(8)$ & $20(8)$ & $1.14(0.66-1.98)$ & 0.639 & \\
\hline Cancer & $27(3)$ & $18(7)$ & $5.55(2.46-12.53)$ & $<0.001$ & $4.69(1.71-12.83)$ \\
\hline Haematologic cancer & $42(5)$ & $18(7)$ & $2.03(1.08-3.81)$ & 0.028 & \\
\hline No comorbidities & $322(37)$ & $48(20)$ & $0.32(0.23-0.46)$ & $<0.001$ & \\
\hline Karnofsky Index < 70 & $230(26)$ & $115(47)$ & $4.05(2.93-5.59)$ & $<0.001$ & $2.50(1.63-3.83)$ \\
\hline Type of infection & & & & $<0.001$ & \\
\hline Community & $436(50)$ & $97(40)$ & 1.0 & & \\
\hline Healthcare associated & $187(21)$ & $75(31)$ & $2.34(1.62-3.39)$ & & \\
\hline Hospital-acquired & $253(29)$ & $71(29)$ & $1.36(0.96-1.95)$ & & \\
\hline Severity of infection & & & & 0.61 & \\
\hline Infection & $255(29)$ & $66(27)$ & 1.0 & & \\
\hline Sepsis & $325(37)$ & $96(40)$ & $1.20(0.83-1.73)$ & & \\
\hline Severe sepsis & $246(28)$ & $70(29)$ & $1.14(0.77-1.67)$ & & \\
\hline Septic shock & $50(6)$ & $11(5)$ & $0.80(0.39-1.67)$ & & \\
\hline SAPS II score, per point & $27 \pm 10$ & $31 \pm 9$ & $1.05(1.03-1.06)$ & $<0.001$ & \\
\hline SOFA score, per point & $2 \pm 2$ & $2 \pm 2$ & $0.99(0.93-1.06)$ & 0.771 & \\
\hline Focus of infection & & & & 0.005 & \\
\hline Respiratory & $345(39)$ & $94(39)$ & 1.0 & & \\
\hline Urinary & $304(35)$ & $100(41)$ & $1.31(0.94-1.83)$ & & \\
\hline Abdominal & $280(21)$ & $33(14)$ & $0.60(0.38-0.94)$ & & \\
\hline Other & $47(5)$ & $16(7)$ & $1.38(0.72-2.64)$ & & \\
\hline Microbiologic documentation & $593(68)$ & $179(74)$ & $1.48(1.07-2.06)$ & 0.020 & \\
\hline Positive blood cultures & $126(14)$ & $46(19)$ & $1.61(1.09-2.40)$ & 0.018 & $1.66(1.04-2.64)$ \\
\hline Infection by a MDR pathogen & $265(49)$ & $89(53)$ & $1.24(0.86-1.79)$ & 0.245 & \\
\hline Infection by an ESKAPE pathogen & $82(15)$ & $30(18)$ & $1.33(0.81-2.17)$ & 0.256 & \\
\hline Inappropriate antibiotherapy & $113(19)$ & $43(24)$ & $1.55(1.01-2.39)$ & 0.044 & \\
\hline
\end{tabular}


mechanism by which certain risk factors independently affect long-term prognosis should be investigated [17]. Another important question is whether prevention or optimal management of these parallel conditions might reduce the long-term death rates [19]. If post-sepsis long-term outcomes are primarily driven by the trajectory of pre-morbid conditions, then interventions targeted at complications attributed to critical illness may not be effective [28]. However all risk factors related to long-term mortality should be considered when addressing individual prognosis and making clinical decision.

This study has several limitations. It is a single center study and although the study design was prospective, data regarding 5 year outcome was collected retrospectively, leading to the exclusion of a minority of patients; nevertheless the final database was of very good quality [29]. We did not have a control population (general population or non-infected sample) to determine the true impact of severe infection. We did not collect data on the ultimate cause of death which would have been very important to identify modifiable prognostic factors that could improve long term outcomes. Secondly, we defined long-term mortality being a 5-year period as there is no consensus towards the definition of long-term outcomes. Finally, we have only studied one long-term outcome leaving others behind (namely those related to quality of life).

Our study has also several strengths; it includes a large cohort of patients, from different hospital settings, with different focus of infection. Previous studies have been restricted to intensive care patients [2, 4-9], specific focus of infection $[20,25,27]$ or specific pathogens $[21,24]$.

\section{Conclusions}

Age, cancer, comorbidities, functional status (Karnovsky Index < 70), SAPS II, severity of infection, positive blood cultures, and infection by a pathogen from the ESKAPE group were independently associated with increased 5year mortality in this large group of patients with severe infection.

We hope that this information will help in the discussion of individual prognosis and clinical decision making.

\footnotetext{
Abbreviations

AU-ROC: Area under the receiver operating characteristics; CAl: Communityacquired infection; CDC: Center for Disease Control; E. coli: Escherichia coli; ESBL: Extended-spectrum beta-lactamase; ESKAPE: Enterococcus faecium, MRSA, ESBL Klebsiella pneumoniae, Acinetobacter baumannii, Pseudomonas aeruginosa and Enterobacter species;" HAl: Hospital-acquired infection; HCAl: Healthcare-associated infections; ICU: Intensive Care Unit; MDR: Multidrug resistant; MIC: Minimum inhibitory concentration; MRSA: Methicillin-resistant Staphylococcus aureus; MSSA: Methicillin-sensitive Staphylococcus aureus; OR: Odds ratio; SD: Standard deviations
}

\section{Funding}

This work was supported by an internal Grant from ASSUCIP (Associação de Apoio à Unidade de Cuidados Intensivos Polivalente - ICU, Hospital de Santo António, Porto, Portugal).

Dr. Cardoso is partially funded by a PhD research grant from the Teaching and Research Department (Departamento de Formação, Ensino e Investigação) of Oporto Hospital Centre.

The funding organisation had no role in the study design; the collection, analysis, or interpretation of the data; neither in the writing of the report nor in the decision to submit the manuscript for publication.

\section{Availability of data and materials}

The datasets used and/or analysed during the current study available from the corresponding author on reasonable request.

\section{Authors' contributions}

TC was responsible for the conception and design of this work. JF and TC performed analysis and interpretation of all the data. JF, IA and TC were major contributors in writing the manuscript. All authors read and approved the final manuscript.

\section{Ethics approval and consent to participate}

This study was approved by the Institutional Review Board of Hospital de Santo António, Oporto Hospital Centre, Portugal, and informed consent was waived due to the observational nature of the study.

Consent for publication

Not applicable

\section{Competing interests}

The authors declare that they have no competing interests.

\section{Publisher's Note}

Springer Nature remains neutral with regard to jurisdictional claims in published maps and institutional affiliations.

\section{Author details}

'Serviço de Medicina, Hospital de Santo António, Largo Prof. Abel Salazar, 4099-001 Porto, Portugal. ²Unidade de Cuidados Intensivos Polivalente, Hospital de Santo António, University of Porto, Largo Prof. Abel Salazar, 4099-001 Porto, Portugal.

Received: 26 January 2017 Accepted: 21 March 2018

Published online: 05 April 2018

\section{References}

1. Schuur JD, Venkatesh AK. The growing role of emergency departments in hospital admissions. N Engl J Med. 2012;367(5):391-3.

2. Alberti C, Brun-Buisson C, Goodman SV, Guidici D, Granton J, Moreno R, et al. Influence of systemic inflammatory response syndrome and sepsis on outcome of critically ill infected patients. Am J Respir Crit Care Med. 2003; 168(1):77-84

3. Leibovici L. Long-term consequences of severe infections. Clin Microbiol Infect. 2013;19(6):510-2.

4. Vincent JL, Sakr Y, Sprung CL, Ranieri VM, Reinhart K, Gerlach H, et al. Sepsis in European intensive care units: results of the SOAP study. Crit Care Med. 2006;34(2):344-53.

5. Martin CM, Priestap F, Fisher H, Fowler RA, Heyland DK, Keenan SP, et al. A prospective, observational registry of patients with severe sepsis: the Canadian Sepsis treatment and response registry. Crit Care Med. 2009;37(1):81-8.

6. Brun-Buisson C, Doyon F, Carlet J, Dellamonica P, Gouin F, Lepoutre A, et al. Incidence, risk factors, and outcome of severe sepsis and septic shock in adults. A multicenter prospective study in intensive care units. French ICU Group for Severe Sepsis. JAMA. 1995;274(12):968-74.

7. Brun-Buisson C, Meshaka P, Pinton P, Vallet B, Group ES. EPISEPSIS: a reappraisal of the epidemiology and outcome of severe sepsis in French intensive care units. Intensive Care Med. 2004;30(4):580-8.

8. Blanco J, Muriel-Bombin A, Sagredo V, Taboada F, Gandia F, Tamayo L, et al. Incidence, organ dysfunction and mortality in severe sepsis: a Spanish multicentre study. Crit Care. 2008;12(6):R158. 
9. Adrie C, Francais A, Alvarez-Gonzalez A, Mounier R, Azoulay E, Zahar JR, et al. Model for predicting short-term mortality of severe sepsis. Crit Care. 2009;13(3):R72.

10. Garner JS, Jarvis WR, Emori TG, Horan TC, Hughes JM. CDC definitions for nosocomial infections, 1988. Am J Infect Control. 1988;16(3):128-40.

11. Friedman ND, Kaye KS, Stout JE, McGarry SA, Trivette SL, Briggs JP, et al. Health care-associated bloodstream infections in adults: a reason to change the accepted definition of community-acquired infections. Ann Intern Med. 2002;137(10):791-7.

12. Boucher HW, Talbot GH, Bradley JS, Edwards JE, Gilbert D, Rice LB, et al. Bad bugs, no drugs: no ESKAPE! An update from the Infectious Diseases Society of America. Clin Infect Dis. 2009;48(1):1-12.

13. Knaus WA, Draper EA, Wagner DP, Zimmerman JE. APACHE II: a severity of disease classification system. Crit Care Med. 1985;13(10):818-29.

14. Le Gall JR, Lemeshow S, Saulnier F. A new simplified acute physiology score (SAPS II) based on a European/north American multicenter study. JAMA. 1993;270(24):2957-63.

15. Karnofsky DA, Burchenal JH. The evaluation of chemotherapeutic agents in cancer. In: Press CU, editor. Evaluation of chemotherapeutic agents C. M. MacLeod; 1949;191-205.

16. Vincent JL, Moreno R, Takala J, Willatts S, De Mendonca A, Bruining H, et al. The SOFA (Sepsis-related organ failure assessment) score to describe organ dysfunction/failure. On behalf of the working group on Sepsis-related problems of the European Society of Intensive Care Medicine. Intensive Care Med. 1996;22(7):707-10. E.

17. Cuthbertson BH, Elders A, Hall S, Taylor J, MacLennan G, Mackirdy F, et al. Mortality and quality of life in the five years after severe sepsis. Crit Care. 2013;17(2):R70.

18. Winters BD, Eberlein M, Leung J, Needham DM, Pronovost PJ, Sevransky JE. Long-term mortality and quality of life in sepsis: a systematic review. Crit Care Med. 2010;38(5):1276-83.

19. Wang HE, Szychowski JM, Griffin R, Safford MM, Shapiro NI, Howard G. Long-term mortality after community-acquired sepsis: a longitudinal population-based cohort study. BMJ Open. 2014;4:e004283. https://doi.org/ 10.1136/bmjopen-2013-004283.

20. Linner A, Sunden-Cullberg J, Johansson L, Hjelmqvist $H$, Norrby-Teglund A, Treutiger CJ. Short- and long-term mortality in severe sepsis/septic shock in a setting with low antibiotic resistance: a prospective observational study in a Swedish university hospital. Front Public Health. 2013;1:51.

21. Yahav D, Yassin S, Shaked H, Goldberg E, Bishara J, Paul M, et al. Risk factors for long-term mortality of Staphylococcus aureus bacteremia. Eur J Clin Microbiol Infect Dis. 2016:35(5):785-90.

22. Stevenson EK, Rubenstein AR, Radin GT, Wiener RS, Walkey AJ. Two decades of mortality trends among patients with severe sepsis: a comparative metaanalysis*. Crit Care Med. 2014;42(3):625-31.

23. Leibovici L, Samra Z, Konigsberger H, Drucker M, Ashkenazi S, Pitlik SD. Long-term survival following bacteremia or fungemia. JAMA. 1995;274(10): 807-12.

24. Laupland KB, Svenson LW, Gregson DB, Church DL. Long-term mortality associated with community-onset bloodstream infection. Infection. 2011; 39(5):405-10.

25. Fatkenheuer G, Preuss M, Salzberger B, Schmeisser N, Cornely OA, Wisplinghoff $\mathrm{H}$, et al. Long-term outcome and quality of care of patients with Staphylococcus aureus bacteremia. Eur J Clin Microbiol Infect Dis. 2004;23(3):157-62

26. Mortensen EM, Kapoor WN, Chang CC, Fine MJ. Assessment of mortality after long-term follow-up of patients with community-acquired pneumonia. Clin Infect Dis. 2003;37(12):1617-24.

27. Lillie PJ, Allen J, Hall C, Walsh C, Adams K, Thaker H, et al. Long-term mortality following bloodstream infection. Clin Microbiol Infect. 2013;19(10): 955-60.

28. Shankar-Hari M, Ambler M, Mahalingasivam V, Jones A, Rowan K, Rubenfeld GD. Evidence for a causal link between sepsis and long-term mortality: a systematic review of epidemiologic studies. Crit Care. 2016;20:101.

29. Cardoso T, Ribeiro O, Aragao I, Costa-Pereira A, Sarmento A. Differences in microbiological profile between community-acquired, healthcare-associated and hospital-acquired infections. Acta Med Port. 2013;26(4):377-84.

\section{Submit your next manuscript to BioMed Central and we will help you at every step:}

- We accept pre-submission inquiries

- Our selector tool helps you to find the most relevant journal

- We provide round the clock customer support

- Convenient online submission

- Thorough peer review

- Inclusion in PubMed and all major indexing services

- Maximum visibility for your research

Submit your manuscript at www.biomedcentral.com/submit 